\title{
Relations of clinical features, subgroups and medication to serum monoamines in schizophrenia
}

\author{
Robert D. Oades ${ }^{1}$, Ansgard Klimke, Uwe Henning, Marie Luise Rao. \\ 2002 Human Psychopharmacology: Clinical and Experimental, 17, 15-27 \\ doi: 10.1002/hup.368
}

From the University of Essen Clinics for Child and Adolescent Psychiatry and Psychotherapy (RDO, $B R)$, the University of Düsseldorf Clinic for Psychiatry and Psychotherapy (AK, UH), and the University of Bonn Clinic for Psychiatry and Psychotherapy (MLR).

\section{ABSTRACT}

Background: Plasma and serum indices of monoaminergic activity reflect partly the illness of schizophrenia (e.g. HVA/deficit syndrome) and sometimes the symptoms (e.g. HVA/anhedonia). But, such studies have rarely taken both metabolites and parent amines or inter-amine activity ratios into account. We hypothesized that comparing the major symptom dimensions to measures of transmitter activity (with and without control for antipsychotic drug treatment) would show differential patterns of activity useful for the design of pharmacological treatments.

Methods: Dopamine (DA), noradrenaline (NA), serotonin (5-HT), their 3 major metabolites and prolactin were measured in the serum of 108 patients with schizophrenia and 63 matched controls: DA D2-receptor blocking-activity was estimated from a regression of butyrophenone displacement in striatum in vitro on to PET reports of drug-binding in vivo. Symptoms were factored into 4 dimensions (disorganized/thought disorder, nonparanoid/negative, ideas-of-reference and paranoid/positive symptoms). Results: (1) Patients' DA activity did not differ from controls: but their 5-HT and NA turnovers increased and the DA/5HT-metabolite ratio was lower. Increased DA-D2receptor occupancy was predicted by decreased DA-metabolism and its ratio to 5-HT-metabolism. (2) Patients had higher levels of NA, DA-metabolites and DA-/5-HT-metabolite ratios on atypical vs. typical drugs. (3) Increased D2-occupancy was associated with lower DA metabolism in paranoid patients but was unrelated to relative increases of 5-HT- and NA-metabolism in nonparanoid patients. (4) Low DA-/5-HT-meta-bolite ratios, high prolactin and low DA-metabolism characterized thought-disordered patients. (5) High DA-/5-HT-metabolite ratios paralleled many ideas-ofreference. The metabolites were sensitive, respectively, to control for D2-occupancy and prolactin. Conclusions: The role of DA in paranoid, and 5-HT in thought-disordered and ideas-of-reference dimensions point both to the mechanisms underlying the features typical of these subgroups and the type of medication appropriate.

\section{Key Words:}

Schizophrenia, paranoid, thought-disorder, ideas of reference, dopamine, noradrenaline, serotonin

\section{Abbreviations:}

COMT, catechol-O-methyl transferase; DA, dopamine; 5-HIAA, 5-hydroxyindoleacetic acid; HVA, homovanillic acid; loR, ideas-of-reference; MHPG, 3-methoxy-4-hydroxy-phenyl-glycol; MAO, monoamine oxidase; NA, noradrenaline; NP, nonparanoid; PN, paranoid; 5-HT, serotonin; ThD, thought-disorder

\section{Acknowledgements:}

We are grateful for the technical assistance of Ms. Margit Geissler in Düsseldorf, Ms. Christine Frahnert in Bonn. We thank Mr. Arndt Hesse and Dr. Bernhard Müller for their help in Essen and we also acknowledge the assistance of Drs. Stefan Bender and Jörg Wolstein with diagnosis. We thank Professors Christian Eggers, Markus Gastpar (Essen), Wolfgang Gaebel (Düsseldorf) and Gudrun Sartory (Wuppertal) for their interest.

\section{Correspondence:}

Robert D. Oades, Biopsychology Research Group, University Clinic for Child and Adolescent Psychiatry, Virchowstr. 174, 45147 Essen, Germany. 1: Supported by grants from the German Research Council (DFG: OA/4-1 \& 2) 


\section{INTRODUCTION:}

Schizophrenia has been and is still thought to be linked to some form(s) of abnormal dopamine (DA) activity (Grace, 2000). The abnormality is proposed to lie with the disruption of cortical regulation of sub-cortical DA activity, and this provides one basis for the cognitive problems of patients with schizophrenia (Breier, 1999) and the continued use of DA antagonism as a treatment strategy (Carlsson et al, 1999). Recent functional and genetic studies have implied a contribution of a low activity allele for catechol-O-methyl transferase (COMT), essential to DA catabolism, to the clinical and cognitive manifestations of schizophrenia (Gasperoni et al, 2001). Nonetheless, evidence continues to be put forward for contributions from dysfunctioning noradrenergic (NA, Friedman et al., 1999) and serotonergic systems (5-HT: Carlsson et al, 1999).

However, despite the widespread acknowledgment of the heterogeneity of schizophrenia few studies have investigated whether indices of the activity of different monoamines or the relationships between them as measured in the circulation are associated with the different clinical pictures presented by patients with schizophrenia. Despite some negative reports (e.g. Galinowski et al 1998; Garver et al 1997; Yoshimura et al 2000), there is a more recent consensus for increased HVA levels to be associated with the negative syndrome (Ribeyre et al 1991; Suzuki et al 1992; Zhang et al 2001) and fewer positive symptoms (Davila et al 1995; Sumiyoshi et al 1997; Kim et al 2000). Reports conflict over whether HVA levels are higher (Nibuya et al 1995) or lower in the deficit vs. non-deficit syndromes (Thibaut et al., 1998). With regard to more specific symptoms, increased HVA has been associated with more anhedonia (Zhang et al 200) and less depression and hostility (Sharma et al 1998). While prominent negative symptoms (Pickar et al 1990) and disorientation (Markianos et al 1992) have been associated with high levels of MHPG, increases of NA and MHPG from low levels have also been related to a good treatment response (Breier et al 1994; Nagamoto et al 1999). Broadly, platelet or plasma levels of 5HT and 5-HIAA are usually increased in patients with schizophrenia (Fukuda et al 1996; Mück-Seler et al 1999; Dursun et al 2000), reflecting numerous earlier studies (Bleich et al 1988), although the differences are not always significant (Markianos et al 1992). Increased metabolism, especially in paranoid patients (Markianos et al 1992) may reflect increased hostility, and impulsivity (Dursun et al 2000), and fewer autistic or depressive features (Alfredsson and Wiesel 1990).

Disparate results often reflect small sample size and treatment, but especially the heterogeneity of the illness, by disregard of the types of patient studied (Reynolds 1995; Zhang et al 2001). The purpose of this report is to go beyond the deficit/non-deficit or positive/negative symptom dichotomies by factor analyzing the main symptom dimensions presented by a large group of patients as a basis for defining subtypes of schizophrenia and seeking their biochemical signatures.

Further, to increase the potential sensitivity of associations between transmitter activity and symptoms, we focus on relationships of the metabolites of the three principal monoamines to their parent amine and to each other. Thus one novel aspect of this study is to take into account the unmetabolized amine in assessing the turnover implicated by metabolite levels. Further, as the catabolic enzymes (MAO and COMT) are in excess in the brain, betweenmetabolite ratios reflect the relative activity between the monoaminergic systems: such comparisons have been but rarely carried out in plasma (Ottong and Garver 1997) and cerebral spinal fluid (Maas et al 1997).

Peripheral measures of monoamines and their metabolites are diluted by sources outside the CNS, nonetheless between a fifth and a third of metabolite levels (HVA, MHPG, 5-HIAA) are reported to derive from the brain (Maas et al 1980; Sternberg et al 1983; Greene and Faull 1989; Kopin 1992; Amin et al 1995). 
There is wide agreement that plasma HVA levels can reflect CNS and CSF measures, psychosis and drug treatment (reviews, Lieberman and Koreen, 1993; Friedhoff and Silva, 1995). Indeed in vivo increases of DA D2 occupancy induced by $\alpha$-methyl-p-tyrosine were tightly correlated to decreased plasma HVA (Laruelle et al 1997).

Carpenter et al (1999) remarked that studies comparing a group of subjects with schizophrenia with another group often report differences without clarifying whether the feature concerned related only to a subgroup of the patients. Our aim is to clarify such an issue for measures of neurotransmitter activity based on groups identified by a factor analysis of the prevalent symptoms (i.e., thought disorder (ThD), negative/nonparanoid symptoms, ideas-of-reference (IoR), and positive/paranoid symptoms).

Such subgroups show quite different problems with information processing that are likely to be modulated by monoaminergic transmission. For example, while patients characterized by ThD are notably impaired in situations demanding of their attentionrelated abilities (Oades, 1982; Liddle and Barnes 1999), those with loR or egodisturbance fail to derive the predicted consequences of intended actions (Frith et al 1994). It has been argued that paranoid/nonparanoid distinctions reflect different lateralized preferences for automatic/ percept and controlled/concept processing strategies (Magaro and Chamrad 1983): this is supported by analyses of selective attention abilities in conditioned blocking performance (Bender et al 2001). We have applied a method for estimating central DA D2-receptor occupancy from serum levels of neuroleptic drug to show that some of these diagnostic differences (paranoid/nonparanoid) and neuropsychological profiles depend on occupancy differences (e.g. verbal fluency and story-recall: Oades et al 2000b). Here, along with prolactin measures, this method is applied to control for the influence of these aspects of medication on the biochemical measures.

\section{MetHODS:}

\section{Subjects:}

In this study 108 patients with DSM-IV criteria for schizophrenia (American Psychiatric Association, 1994) from the Child, Adolescent and Adult University Psychiatry Clinics were compared with 63 healthy controls, recruited by advertisement and paid for their participation. The groups were closely matched for age, education, socio-economic family status and handedness (Table 1 ).

Patients were admitted consecutively for functional psychosis. The initial diagnosis was made by the senior ward physician. They were re-examined for entry to the study by two senior physicians of the research group (S.B \& J.W.: DSM-IV, criteria A-E): affective, schizoaffective and schizophreniform psychoses were excluded. Patients were also screened to exclude other major psychiatric or somatic illness, alcohol abuse in the last 5 years and substance abuse other than nicotine. Schizophrenia subtypes were defined by DSM-IV criteria, whereby the undifferentiated type was regarded as a residual category that contrasts with the paranoid, disorganized and catatonic subtypes. The exclusion criteria for healthy participants, based on a semi-structured interview, were the same as for the patients. In addition they reported no family history of psychotic illness, nor that they had previously consulted with a psychiatrist or psychologist.

Symptom severity was rated with the Positive and Negative Syndrome Scale (PANSS: Kay et al 1992). As Schneiderian ideas-ofreference (ego-disturbance) and thought disorder are under- represented in this scale, the relevant items from the Scale for Assessment of Positive Symptoms (SAPS: Andreasen \& Olsen 1982) were also scored. Motor side-effects and handedness were rated but are not part of the present analysis. Following approval from the Medical Centre Ethics Committee, informed signed consent was obtained from each patient and the responsible care-giver, and from each healthy participant. 


\section{Table 1}

Demographic and Clinical Data (Means \pm standard deviation): a) 108 patients and 63 controls providing biochemical data, and b) 72 patients and 37 controls with a full set on 3 monoamine and 3 metabolite measures (excluding outliers)

\begin{tabular}{|c|c|c|c|c|c|c|c|c|c|}
\hline \multirow[b]{2}{*}{ Age } & \multirow[b]{2}{*}{ (years) } & \multicolumn{2}{|c|}{$\begin{array}{l}\text { Schizophrenics } \\
\text { (a) }\end{array}$} & \multicolumn{2}{|c|}{ Controls } & \multicolumn{2}{|c|}{$\begin{array}{l}\text { Schizophrenics } \\
\text { (b) }\end{array}$} & \multicolumn{2}{|c|}{ Controls } \\
\hline & & 33.3 & $(10.9)$ & 32.5 & $(11.0)$ & 32.1 & $(10.4)$ & 32.7 & $(9.9)$ \\
\hline Gender & $(\mathrm{m} / \mathrm{f})$ & \multicolumn{2}{|c|}{$68 / 40$} & \multicolumn{2}{|c|}{$34 / 29$} & \multicolumn{2}{|c|}{$48 / 24$} & \multicolumn{2}{|c|}{$23 / 14$} \\
\hline \multicolumn{2}{|c|}{ Socio-economic group $^{1}$} & 4.5 & $(2.0)$ & 4.9 & $(1.6)$ & 4.4 & $(2.0)$ & 4.9 & (1.7) \\
\hline Education & (years) & 13.2 & $(3.7)$ & 13.8 & $(3.0)$ & 13.1 & $(3.3)$ & 14.0 & $(3.2)$ \\
\hline IQ & (short APM) & 7.3 & $(2.6)$ & 9.9 & $(1.9)$ & 7.7 & $(2.6)$ & 10.0 & $(2.0)$ \\
\hline Handedness & (Edinburgh) & 17.5 & $(8.5)$ & 18.9 & $(5.3)$ & 16.9 & $(9.2)$ & 18.7 & $(6.4)$ \\
\hline Onset-Age & (years) & 23.6 & $(8.4)$ & & & 23.5 & $(8.3)$ & & \\
\hline \multicolumn{2}{|c|}{ First admission } & 25.1 & $(9.6)$ & & & 24.7 & $(9.5)$ & & \\
\hline \multicolumn{2}{|c|}{ Duration of illness (years) } & 9.5 & $(8.0)$ & & & 8.7 & $(7.1)$ & & \\
\hline \multicolumn{2}{|c|}{ Extrapyramidal symptoms } & 5.8 & $(5.6)$ & & & 5.1 & $(3.8)$ & & \\
\hline \multicolumn{2}{|l|}{ AIMS } & 8.4 & $(2.9)$ & & & 8.5 & $(2.9)$ & & \\
\hline \multicolumn{3}{|c|}{ Antipsychotic drug dose $(\mathrm{CPZ})^{2} 665$} & $(328)$ & & & 631 & $(334)$ & & \\
\hline Biperidene & (mg/day) & 4.2 & $(1.8)$ & & & 4.2 & $(1.6)$ & & \\
\hline
\end{tabular}

1. Scale 1-7, (Brauns et al., 1997): AIMS, Abnormal involuntary movement scale ( $\mathrm{n}=68 / 108$ and 41/72); APM, Advanced progressive matrices; CPZ, chlorpromazine equivalents, excluding 2 patients without medication; Biperidene is an anticholinergic drug $(\mathrm{n}=15 / 108$ and 9/72); PANSS, Positive and negative syndrome scale;

Table 2

Levels of monoamines, metabolites and turnovers (metabolite/amine) in patients with schizophrenia (SCH) and control subjects (CON):

(Data-providing samples from 108 patients and 63 controls : SD in italics)

\begin{tabular}{|c|c|c|c|c|c|c|c|c|c|}
\hline & $\begin{array}{l}\text { DA } \\
\mathrm{pg} / \mathrm{ml}\end{array}$ & $\begin{array}{l}\text { HVA } \\
\mathrm{ng} / \mathrm{ml}\end{array}$ & TR & $\begin{array}{l}\text { NA } \\
\mathrm{pg} / \mathrm{ml}\end{array}$ & $\begin{array}{l}\text { MHPG } \\
\mathrm{ng} / \mathrm{ml}\end{array}$ & TR & $\begin{array}{l}5-\mathrm{HT} \\
\mathrm{pg} / \mathrm{ml}\end{array}$ & $\begin{array}{l}\text { 5-HIAA } \\
\mathrm{ng} / \mathrm{ml}\end{array}$ & $\mathrm{TR}$ \\
\hline $\mathrm{SCH}$ & $\begin{array}{l}142 \\
96\end{array}$ & $\begin{array}{r}14.21 \\
8.01\end{array}$ & $\begin{array}{l}129.44 \\
\quad 117.10\end{array}$ & $\begin{array}{r}1.160 \\
.66\end{array}$ & $\begin{array}{l}4.913 \\
2.63\end{array}$ & $\begin{array}{r}5.863 \\
6.04\end{array}$ & $\begin{array}{r}160.74 \\
72.06\end{array}$ & $\begin{array}{r}12.46 \\
5.66\end{array}$ & $\begin{array}{r}0.101 \\
.09\end{array}$ \\
\hline $\mathrm{N}$ & 90 & 96 & 85 & 97 & 102 & 97 & 100 & 99 & 98 \\
\hline $\mathrm{CON}$ & $\begin{array}{r}118 \\
81\end{array}$ & $\begin{array}{r}12.52 \\
6.05\end{array}$ & $\begin{array}{r}126.74 \\
84.37\end{array}$ & $\begin{array}{r}1.025 \\
.54\end{array}$ & $\begin{array}{l}5.252 \\
2.01\end{array}$ & $\begin{array}{r}6.174 \\
3.22\end{array}$ & $\begin{array}{l}159.41 \\
67.51\end{array}$ & $\begin{array}{l}12.99 \\
9.17\end{array}$ & $\begin{array}{r}0.089 \\
.06\end{array}$ \\
\hline $\mathrm{N}$ & 51 & 57 & 50 & 59 & 59 & 59 & 61 & 58 & 57 \\
\hline \multicolumn{10}{|c|}{$\underline{\text { Number of missing samples / cut-off }}(=$ mean $\pm 2 S D)$} \\
\hline $\mathrm{SCH}$ & $15 / 3$ & $10 / 2$ & $19 / 4$ & $7 / 4$ & $3 / 3$ & $10 / 1$ & $3 / 5$ & $6 / 3$ & $6 / 4$ \\
\hline $\mathrm{CON}$ & $9 / 3$ & $3 / 3$ & $10 / 3$ & $1 / 3$ & $0 / 4$ & $2 / 2$ & $0 / 2$ & $4 / 1$ & $4 / 2$ \\
\hline
\end{tabular}




\section{Medication:}

The study took place during the patients' stay on the ward following clinical stabilization, 6 weeks after admission (range 4-8 weeks). Antipsychotic drugs were administered to the patients according to the clinical requirements. The dose was normalised to chlorpromazine equivalents (CPZ) according to Benkert and Hippius (1986), Rey et al., (1989), Schulz et al., (1989), Kane (1996) and correspondence with the firms supplying olanzapine and sertindole. Two male patients were without medication at the time of testing, 49 (63\% male) were administered typical antipsychotic drugs or risperidone, 43 (67\% male) received atypical medication (clozapine, olanzapine or sertindole), and 15 ( $47 \%$ male) had a combination of both types of drug. In terms of the diagnosis of paranoid $(n=76)$ vs. nonparanoid $(n=31)$ schizophrenia 40 vs. 9 received typical, 25 vs. 18 received atypical and 11 vs. 4 received both types of medication (Table 1).

\section{Sample Analysis:}

A $30 \mathrm{ml}$ blood sample was taken at 08.00 in the morning ( $\pm 30 \mathrm{~min}$ ) after 10 hours of fast and rest and before medication, smoking, exercise and breakfast. The sample was centrifuged for $10 \mathrm{~min}$ at $2000 \mathrm{~g}$ and the serum stored at $-70^{\circ} \mathrm{C}$ until analysis. All samples were analyzed blind to their origin by reversed phase high performance liquid chromatography with a glassy carbon electrochemical detector using internal standards. Separate isocratic determinations were run for a) DA and NA, b) 5-HT with organic-sodium dihydrophosphate mobile phases (modified after Eriksson and Persson 1982), c) HVA, 5-HIAA, (Gypta and Whelton 1992) and d) MHPG with organic sodiumacetate mobile phases (Minegishi and Ishizaki 1984). Intra- and inter-assay coefficients of variation were DA 11.6/8.9\%, NA 11.6/9.1\%, 5-HT 2.3/9.2\%, HVA 7.1/19.8\%, 5-HIAA 6.0/7.3\% and MHPG 6.9/18.1\%, respectively. Recovery ranged from ca. $74-80 \%$ with the following sensitivities $(\mathrm{ng} / \mathrm{mL})$ for DA 0.5 , NA 0.01, 5-HT 1.0, HVA and 5-HIAA 1.25, and MHPG 1.0.
Serum 5-HT measures were taken to provide comparable ratios between monoamines. Circulating 5-HT levels can be expressed in terms of platelet numbers, their protein content, or per unit volume of blood, serum or platelet-rich plasma. The first two methods may be contaminated by nonplatelet derivatives and their proteins, while the latter 3 types of measure can vary with 5HT release from the platelets into the serum. Nonetheless, a high correlation between platelet and circulating levels with excellent intra-individual replicability at 3 months has been repeatedly reported for healthy subjects (e.g. Jernej et al 2000; Croonenberghs et al 2000). Our values match those reported by Jernej et al and 5 studies discussed (98-312 $\mathrm{ng} / \mathrm{ml})$, and are somewhat lower than in 3 reports on platelet-rich plasma and serum $(269-271 \mathrm{ng} / \mathrm{ml})$. Turnover rates are similar to a report on plasma values (Dursun et al 1997). The scarcity of outliers ( \pm 2 SD) is comparable with the other monoamines (Table 2), does not point to irregular platelet-release and emphasizes the lack of variability.

Serum antipsychotic drug levels were estimated according to Rao (1986) with a radioreceptor assay technique using ${ }^{3} \mathrm{H}$ spiroperidol as ligand with increasing concentrations of haloperidol and a DA D2receptor preparation from pig striatum. The resulting 'neuroleptic unit' ( DA D2-receptor antagonist binding activity in relation to the haloperidol standard) is the extent of displacement produced by $100 \mu \mathrm{L}$ of serum containing haloperidol at a concentration of 1 $\mathrm{nmol} / \mathrm{mL}(0.37 \mathrm{ng}$, also the lower limit of detection). The intra- and inter-assay coefficients of variation were $5 \%$ and $8 \%$, respectively.

Central DA D2 receptor-occupancy was inferred from the antipsychotic dose versus D2-receptor occupancy, reported in the literature (Oades et al 2000b). Separate linear regression analyses for each drug related dose to occupancy. Thus, the approximate percentage occupancy for a given dose was computed from the occupancy regression: this could not be calculated for drugs for which 
there were no published PET data ${ }^{1}$. Occupancy data were available from 76 patients. Lastly serum prolactin levels were determined by a radio-immunoassay (Biosource, Nivellis, Belgium) resulting in intra- and inter-assay coefficients of variation of $5 \%$ and $8 \%$, respectively.

\section{Data treatment:}

The original sample consisted of 108 patients and 63 healthy controls. This number was reduced for each monoamine or metabolite measure by $0-4$ by the removal of outliers (cut-off criterion \pm 2 S.D.). Data for individual measures and the covariates, missing for technical reasons, reduced the sample further by $0-15$ per measure leaving 73 patients and 37 controls providing a full set of data for the 3 monoamines and their 3 metabolites (Table 2). Applying these criteria for the separate statistical consideration of a complete set of metabolite ratios resulted in a loss of data from a further 10 patients.

A consideration of the sub-types of schizophrenia was based on a factor analysis of the symptom ratings that resulted in 4 dimensions (Bender et al 2001): (1) disorganized (including thought disorder), (2) nonparanoid (largely negative symptoms), (3) ideas-of-reference and (4) paranoid (positive symptoms). Thus, comparisons contrasted paranoid (PN) with nonparanoid (NP) groups, and with respect to the median, high vs. low levels of thought-disorder (ThD) and ideas of reference (loR).

As most of the biochemical data did not show a normal distribution, they were converted to their natural logarithms. Spearman rank correlations were used to explore relationships, especially for determination of the need to use covariates in the diagnosis by biochemical measure analyses (e.g. demographic, clinical features and nicotine use). To avoid comparing related

\footnotetext{
1 PET data were not available at the time the regression analyses were calculated for the following antipsychotic drugs that were administered to at least one patient: bromperidol, chlorprothixene, fluphenazine, levomepromazine, perazine, promethazine, sulpiride, sertindole and zotepine.
}

measures, separate multivariate analyses of variance (MANOVA) were used to examine clinical and biochemical group differences and interactions for (1) the 6 individual measures of the mono-amines and metabolites (DA, NA. 5-HT, HVA, MHPG, 5-HIAA), and (2) the 5 ratios (HVA/DA, MHPG/NA, 5-HIAA/5-HT, HVA/MHPG, HVA/5-HIAA). One-way ANOVAS specify the locus of significant effects. The expected relationships of DA D2 binding measures and prolactin levels with monoamine activity are described using a linear step-wise backward regression to determine the predictor variable. After contrasting patient with non-patient groups we consider the effect of medication followed by the different patient subgroups.

RESULTS:

\section{Whole group comparisons:}

There were no differences between patient and control groups on age, years in education and parental socio-economic class (Table 1). But, as several biochemical measures correlated with age and IQ in healthy subjects and the relationships changed when patients were considered, these variables were used as covariates in MANOVA analyses (controls: age/IQ, respectively, with 5-HIAA, $r=$ $+0.41 /+0.33, \mathrm{p}<.002 / .013 ; 5-\mathrm{HT}$ turnover $r=$ $+0.24 /+0.42, p<.07 / .001 ;$ HVA/5-HIAA, $r=-$ $0.31 /-0.28, p<.03 / .05 ; \mathrm{HVA} / \mathrm{MHPG}, r=-0.27$, $p<.05$, IQ not significant). A pair-wise t-test comparison between males and females showed no within-group gender difference on any biochemical measure.

Two-way MANCOVAS FOR group (patient and control) by biochemical measure (6 amines and metabolites, or 5 ratios) were significant (respectively, $\mathrm{F}_{6,101}=2.2, p=.05$; $F_{5,93}=3.7, p=.004$ : Fig. 1). The first effect was explained by lower MHPG levels in the patients $\left(F_{1,106}=6.8, p<.01\right)$. The lower NA turnover implied was confirmed in the analysis of ratio measures $\left(F_{1,97}=10.5, p<\right.$ .002). The analysis of metabolite ratios showed that the patients had a higher 5-HT turnover, that was further reflected in a lower HVA/5-HIAA ratio $\left(\mathrm{F}_{1,97}=4.0\right.$ and $5.1, p<.05$ and .03 , respectively). There were no group 
differences for measures of DA, HVA or DA turnover.

Oades et al (2000b) reported a higher DA D2-occupancy in female vs. male patients with schizophrenia (69\% vs. $61 \%$ ): these values were predicted to a similar degree in separate stepwise backward regressions for 2 measures among the amines and metabolites $\left(\mathrm{F}_{1,46}=5.6\right.$, $\left.p=.007, \mathrm{R}^{2}=19.6, \mathrm{n} 49\right)$ and 3 of their ratios $\left(\mathrm{F}_{3,41}=2.8, p=.05, \mathrm{R}^{2}=16.9, \mathrm{n} 45\right) . \mathrm{NA}$ and HVA had negative partial correlations with DA D2-occupancy ( $r=-0.31 /-0.36, p=.003 / .013$, respectively). HVA/MHPG and NA turnover were positively correlated $(r=+0.33 /+0.3$, $p=.029 / .05$, respectively), while HVA/5-HIAA was negatively associated with DA D2occupancy ( $r=-0.39, p=.009$ ). In contrast prolactin levels were not significantly predicted by the biochemical measures, although NA and 5-HT levels had nonsignificant negative relationships. [As expected, prolactin levels were higher after treatment with typical ( $n=44)$, typical and atypical $(n=15)$ vs. atypical $(n=40)$ types of antipsychotic drugs, [respectively, 1.11 SD 1.0; 1.07 SD 0.9, 0.44 SD $0.4 \mathrm{nmol} / \mathrm{L} ; F_{2,96}=12.3, p<$ $.00002)]$.

\section{Medication:}

Considering the whole patient group, Figure 2 shows the result of comparing the biochemical measures for patients receiving typical antipsychotic medication alone, atypical medication alone, or after simultaneous treatment with drugs from both categories. A clear increase of HVA/5-HIAA, HVA and DA was followed by a modest increase of NA and a non-significant increase of MHPG in those receiving atypical (with or without adjunctive typical agents) vs. typical medication.

A comparison of the effects of dose (chlorpromazine equivalents, CPZ), DA D2occupancy and prolactin (reflecting the dopaminergic and serotonergic aspects of the agents administered) is shown in Figure 2. This shows that the HVA (and NA) changes were dependent on central DA D2-occupancy, as the significance of the ANOVA was removed, while DA and HVA/5-HIAA measures were only partially affected. Controlling for prolactin levels emphasized the HVA/5-HIAA increase after atypical agents without any marked effect on the dopaminergic measures.

We contrasted paranoid patients on atypical vs. typical agents (n 14 vs. 25 , with a further 7 receiving both: data not shown). As above, the increased HVA levels after atypical agents proved no longer significant after controlling for DA D2-occupancy, but covariance for prolactin left DA measures intact and uncovered a modest increase of 5HT for those only receiving typical neuroleptic drugs. Similarly the increased HVA/5-HIAA ratio after atypical agents was no longer significant after controlling for DA D2occupancy, but the significance of the difference was increased after covariance for PRL levels. These results may reflect the lower DA D2-occupancy expected after atypical agents, and their higher serotonergic affinity. The only datum showing a modest trend among the non-paranoid patients was an increase of DA levels after atypical drug treatment. But with only 20 patients divided between the three groups, this was not explored further.

Effects of other categories of adjunctive medication were also briefly explored. Noradrenergic: Two patients received $\beta$ noradrenergic drugs and were not considered in these analyses. Cholinergic: Administration of the anticholinergic biperidene $(n=15)$ yielded no correlations with other biochemical parameters. Nicotine: Nicotine intake in 26 control smokers (15 mg/d SD 10.3) was not correlated with any biochemical measure. In 71 patients who smoked, nicotine intake (24 $\mathrm{mg} / \mathrm{d}$ SD 12.5) correlated negatively with MHPG and NA turnover $(r=-0.23 /-0.21, p=$ $.02 / .04)$ but was modestly associated with increasing DA levels $(r=+0.2, p=.09)$. Benzodiazepines: The 13 patients on Lorazepam showed no significant biochemical changes with respect to other patients, despite their rather low DA turnover and slightly increased 5-HT turnover. Serotonin reuptake inhibitors : The 8 patients receiving these drugs showed lower 5-HT levels (56.8 SD 61 vs. 183.1 SD $84 ; t=+4.8, p=.0001$ ) with respect to the other patients and those on typical antipsychotic drugs, and high DA 
Figure 1

Monoamine and metabolite levels (above), with the turnover ratios for each and between-metabolite ratios for HVA (below) in patients with schizophrenia (n73) vs. healthy controls (n37): 5-HT turnover was larger in schizophrenia contributing to the smaller HVA/5-HIAA ratio (\#, $p<.05)$ : MHPG levels $(*, p<.01)$ and NA turnover $(* *, p<.002)$ were lower in schizophrenia.

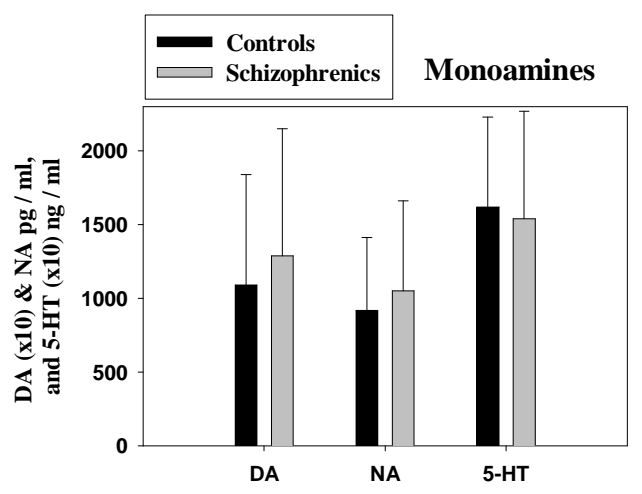

Utilization or Turnover Ratios (TR)

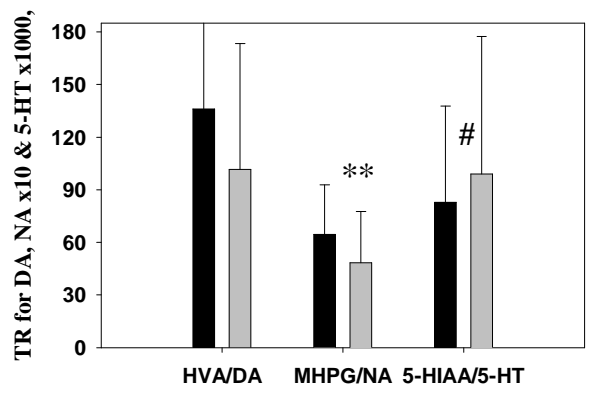

turnovers at levels above those on atypical antipsychotic drugs alone (233 SD 180 vs. 169 SD 238; $\mathrm{t}=-2.6, p=.018)$. This resulted in a modest increase of HVA/5-HIAA ratios (2.4 SD 1.8 vs. 1.4 SD $1.0 ; \mathrm{t}=-2.0, p=.07)$. Risperidone: Dose tended to be correlated positively with DA levels (n 10, $r=+0.56, p<$ .09), but in the 7 paranoid patients dose correlated positively with 5-HT turnover ( $r=$ $+0.67, p=.097)$.

\section{Subgroup comparisons: paranoid/non- paranoid diagnosis:}

A significant difference for those patients with (46) vs. those without (17) a diagnosis of paranoid schizophrenia $\left(F_{5,55}=2.8, p<.03\right)$ was explained by the paranoid patients showing a lower turnover for DA and NA $\left(F_{1,59}\right.$ $=3.2 / 4.3, p<.08 / .04$, respectively). The relatively low DA activity in paranoid patients reflected lower HVA levels $\left(\mathrm{F}_{1,68}=3.9, p<.05\right)$ that in turn explained in part the significantly
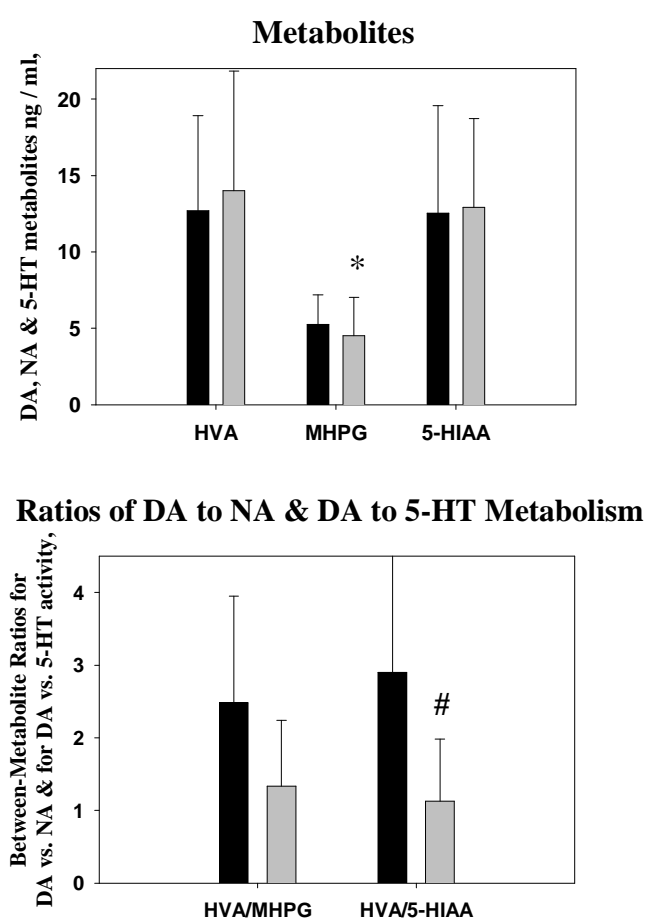

lower HVA/5-HIAA ratio $\left(\mathrm{F}_{1,59}=4.0, p<.05\right.$ : Fig. 3).

Medication in terms of chlorpromazine equivalents or alterations of prolactin levels did not differ between groups (for PN vs. NP, mean CPZ 702 SD 332 vs. 639 SD 385; PRL 0.94 SD 1.0 vs. 0.67 SD $0.8 \mathrm{nM} / \mathrm{L}$ ), and use of CPZ as a covariate did not alter the significance of the biochemical analyses. However, Oades et al (2000b) reported increased DA D2-occupancy in these paranoid patients: these values also differed significantly in the patients with biochemical data (PN 66\% SD 19 vs. NP 54\% SD 23), and use of these values as a covariate removed the significance of DA turnover differences while leaving the NA turnover and HVA/5-HIAA differences intact. Thus while DA receptor-binding differences between paranoid and non-paranoid patients explained the lower DA activity in paranoid patients, the relative increase of $5-\mathrm{HT}$ metabolism to DA metabolism and the increased NA turnover in non-paranoid patients were independent of antipsychotic medication 
Figure 2

Comparison of monoamine measures in groups of patients with schizophrenia treated with typical $(\mathrm{T})$, atypical (A) or typical and atypical antipsychotic drugs ( $\mathrm{T}+\mathrm{A})$.

Above. After A and T+A treatment HVA increased, dependent on central DA D2 occupancy (cf. controlled by DA D2-occupancy in MANCOVA, right): DA levels also increased, somewhat dependent on dose (controlled by CPZ in MANCOVA, right): modest trend for NA increase (also dependent on DA D2 occupancy).

Below. Marked increase of HVA/5-HIAA ratio after atypical drug treatment (A, T+A) that is only affected by DA D2-occupancy to a small degree (cf. MANCOVA right)

Treatment with atypical vs. typical antipsychotic drugs $(A$ or $\mathbf{T}+A)$ increases catecholamines and their metabolites, but not the indoleamines

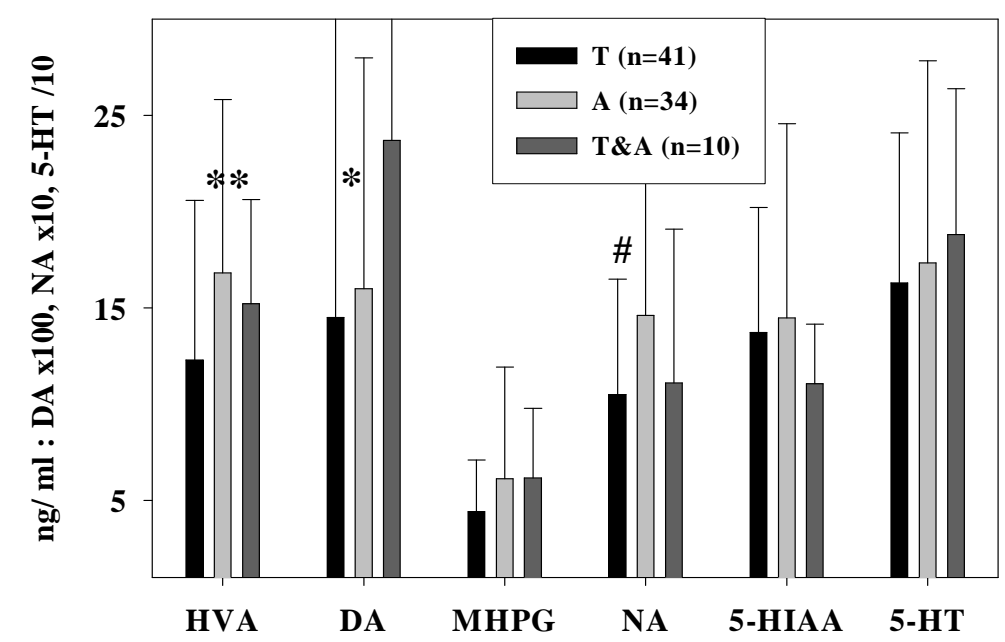

$$
\begin{aligned}
& \text { Manova: } F_{12}, 126=2.0, p=0.02 \\
& \text { Covariate } 0 \text { age/IQ + CPZ or D2 or PRL } \\
& \begin{array}{llllll}
\mathrm{dF} & 2,68 & 2,66 & 2,65 & 2,43 & 2,60
\end{array} \\
& \text { HVA : F }=\begin{array}{lllll}
3.43 & 2.93 & 3.27 & 0.74 & 3.46
\end{array} *
\end{aligned}
$$

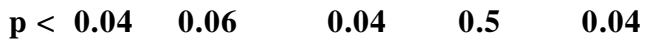

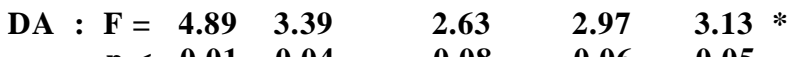

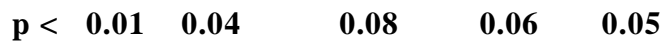

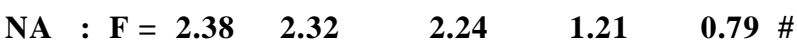

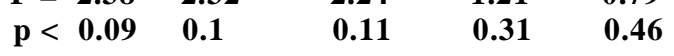

Monoamine \& metabolite levels after T (typical), A (atypical) or $\mathbf{T}+\mathbf{A}$ (typical \& atypical antipsychotic drugs)

Atypical antipsychotic drugs ( $A$ or $T+A)$ increase the ratio of DA-to-5-HT metabolism (HVA/5-HIAA)
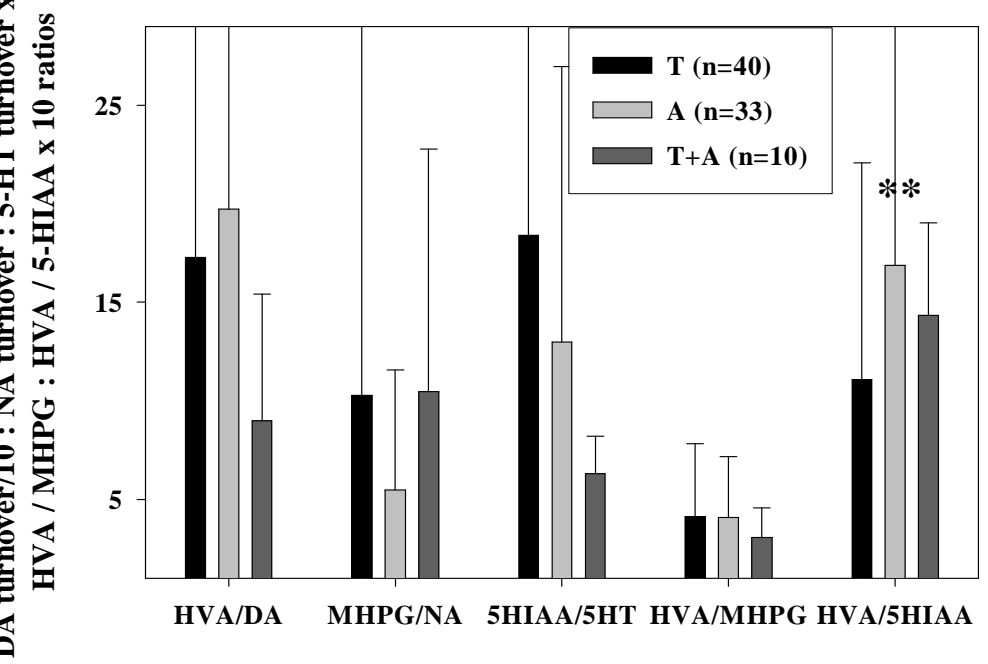

dF

2,59

2,57

2,56

2, 39

2,52

HVA/5-HIAA :

$\begin{array}{lllll}\mathbf{F}=5.13 & 4.77 & \mathbf{5 . 4 8} & \mathbf{3 . 5 6} & \mathbf{6 . 4 4} * * \\ \mathbf{p}<0.008 & \mathbf{0 . 0 1 2} & \mathbf{0 . 0 0 6} & \mathbf{0 . 0 3 8} & \mathbf{0 . 0 0 3}\end{array}$

Monoamine utilization ratios, and intermetabolite ratios after $T$ (typical), A (atypical) or $\mathbf{T}+\mathrm{A}$ (typical \& atypical antipsychotic drugs) 


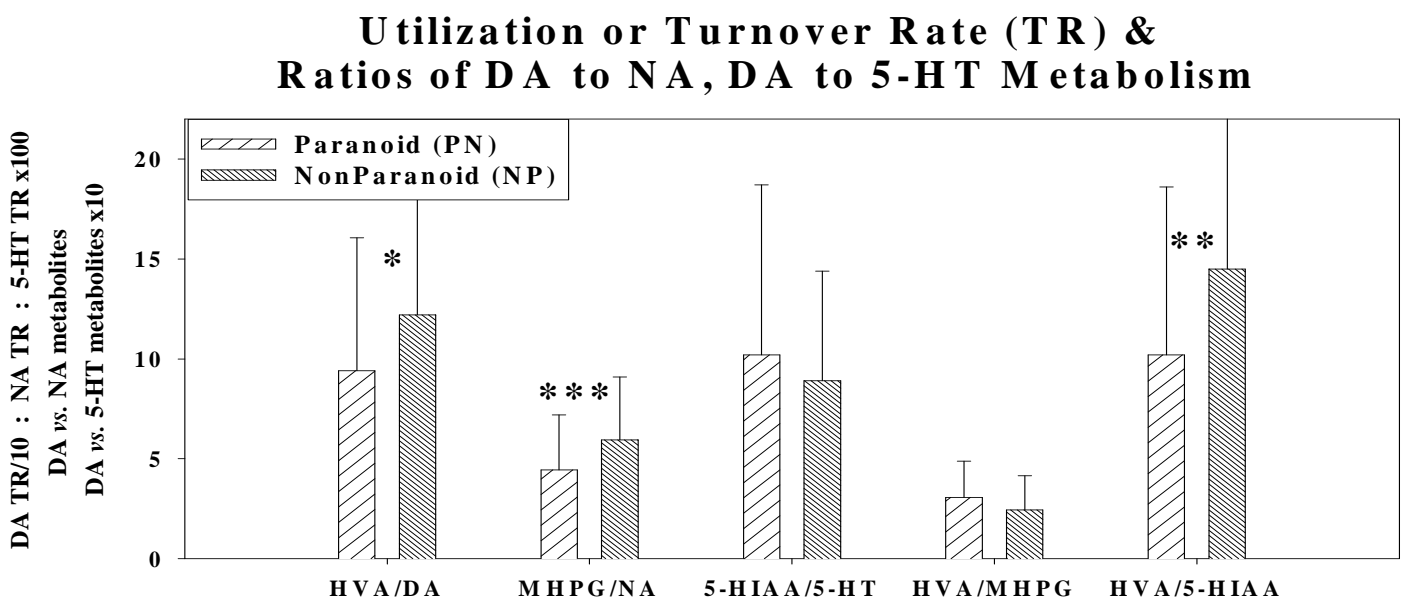

Figure 3

The turnover ratios for 3 monoamines and between-metabolite ratios for HVA in patients with paranoid (n46) vs. those with non-paranoid schizophrenic diagnoses (n17): Higher levels in NP patients, $* p<.08, * * p<.05, * * * p<.04$

\section{Subgroup comparisons: high / low ratings of thought-disorder:}

Thought-disorder was the first dimension of the factor analysis of the symptom ratings. The MANOVA of the ratio measures of monoamine activity $\left(\mathrm{F}_{5,54}=2.1, p<.08\right)$ showed that patients with much thoughtdisorder exhibited lower HVA/5-HIAA ratios $\left(F_{1,59}=4.3, p<.04\right)$. This difference in the relative metabolism of DA and $5-\mathrm{HT}$ was not explicable by HVA levels, that proved to be higher in those with low thought-disorder ratings $\left(F_{1,67}=4.2, p<.04\right.$ : figure 4$)$.

Changes of DA activity were not reflected by differences in chlorpromazine equivalents or DA D2 occupancy (low vs. high thought disorder: mean CPZ 751 SD 321 vs. 784 SD 344, DA D2 66 SD 15 vs. 65 SD 20\%). Neither, used as a covariate, altered the result of the MANCOVA. However, prolactin levels were higher in the high thought-disorder group (0.98 SD 0.96 vs. 0.65 SD $0.74 \mathrm{nM} / \mathrm{L}$ ). The significance was only $10 \%$ for the 23 vs. 22 subjects providing biochemical data, and accordingly use of PRL as a covariate only rendered the MANCOVA modestly nonsignificant ( $p=.053)$ : but, measures differed at the $1 \%$ significance level for all patients for whom PRL levels were determined. Thus with this and the absence of group differences or covariate influence of D2-occupancy or medication dose it is hypothesized that a 5-HT component may enhance the expression of thought disorder, facilitate prolactin release and lower HVA/5-HIAA ratios.

\section{Subgroup comparisons: high / low ratings of ideas-of reference (IoR):}

IoR was the third dimension of the factor analysis of the symptom ratings. There were tendencies for DA and 5-HT turnover to be increased in the patients expressing loR (both: $\mathrm{F}_{1,59}=3.9, p<.05$ : Figure 4$)$ : increases of HVA/5-HIAA also tended to be significant after covarying for drug doses.

When the analyses were covaried for DA D2-occupancy, the significance of DA activity disappeared while that for 5-HT activity increased. The opposite held for covarying with prolactin levels (i.e. DA activity increased significantly, and the 5-HT activity change was non-significant, implying a prolactin-5-HT relationship). This may be viewed against a background of the absence of significant group differences on CPZ, PRL and DA D2 occupancy (low [n25] / high loR [n20], respectively: CPZ 690 SD 329 vs. 862 SD 312; DA D2-occupancy 66 SD $20 \%$ vs. 64 SD 16\%; PRL 0.94 SD 0.88 vs. 0.66 SD $0.83 \mathrm{nmol} / \mathrm{L})$. 


\section{Figure 4}

Left: Metabolite levels for 3 monoamines and between-metabolite ratios for HVA in patients with little (n37) or much thought-disorder (n38): Patients with much thought disorder had lower HVA and HVA/5-HIAA ratios ** $p<.04$ and a trend to lower HVA/MHPG ratios, \# $p<.08$ ).

Right: Monoamines levels and their turnover ratios in patients expressing few (n36) or many Ideas-ofReference (n27). Those with many Ideas-of Reference had higher turnovers for 5-HT and DA (** $p<$ $.05)$, and the ratio of their metabolites was also higher after covarying for CPZ (** $p<.05)$.

Monoamine Metabolites \& the Ratio of DA to NA \& 5-HT Metabolites

Patients with much vs. little Thought Disorder (ThD)

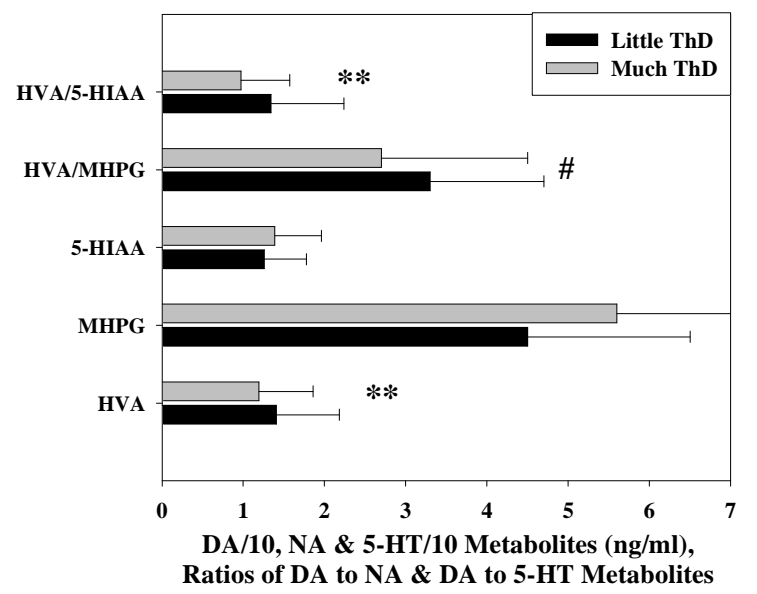

\section{DISCUSSION:}

Our analysis suggests that patterns of serum indicators of monoamine activity vary with the predominant symptom dimensions and that an additional effect of antipsychotic medication can be shown by taking account of estimated DA D2-receptor occupancy and prolactin release. We discuss briefly the effect of atypical vs. typical medication followed by the 4 groups of schizophrenias studied.

\section{Medication:}

The most significant difference between patients receiving typical or atypical antipsychotic drugs was the increased HVA/5HIAA ratio recorded in those on atypical medication. This was not due to differences of 5-HIAA or 5-HT levels (Figure 2 top), but rather the increased circulation of HVA. It should be noted that the relation of HVA to MHPG did not change due to a modest increase of MHPG. This in turn implies that the HVA recorded did reflect DA and not only NA metabolism. This interpretation is supported by the slight but significantly increased
Monoamine Turnover / Utilization and Between-Metabolite Ratios

in Patients with many vs. few Ideas-of-Reference (IoR)

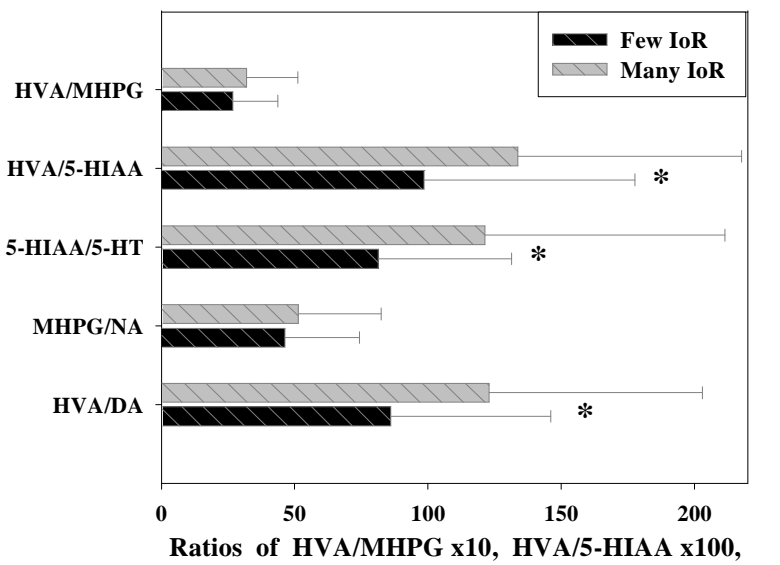

and Turnover Ratios for DA x1, NA x10 \& 5-HT x1000

amount of DA recorded. But did the increased HVA reflect neural transmission? An alternative explanation is that the HVA reflected the breakdown of unused but released DA. The modest increase of DA measured would have been only partly compromised by the poor blood-brain transport of DA: other peripheral sources would have persisted. Thus one may argue that there was no significant HVA/DA increase as the levels of both components increased. But, the feature that argues strongly for increased postsynaptic DA activity after treatment with atypical drugs is that the HVA increases lost significance after covarying for the estimated occupancy of the D2-binding site (Figure 2).

This result is concordant with the increase of DA and its metabolites following clozapine treatment in cortical and subcortical regions of rat brain (Cartmell et al 2001), and in plasma from patients with schizophrenia, where Green et al (1993) reported major HVA and more gradual DA and MHPG increases. Caution in too close an interpretation of the 
HVA increase is necessary as clozapine enhances NA metabolism (as is evident in our results) and about a quarter of the HVA measured peripherally may be contributed from (central) NA metabolism (Amin et al 1995). One limit to the measures and conclusions drawn here is the insensitivity to 5-HT-related measures. However, while it has been suggested that too much 5 -HT derives from peripheral sources for a signal to emerge from CNS changes (Lieberman and Koreen, 1993), one would expect drug-induced alterations to affect the activity of both sources: further, Maas et al (1980) reported that up to a third of the 5-HIAA excreted, derived from central sources. A second limit is the limited proportion of DA that may leak from the brain to the peripheral circulation. How-ever, again one would expect the drugs to have a similar action on peripheral DA activity, and increased DA levels in schizophrenia have been noted else-where (Rao et al. 1990) notably after clozapine treatment (Schulz et al 1994; 1997).

\section{Schizophrenia as a group:}

Compared to healthy controls the patients evidenced a) no differences of DA metabolism, b) lower NA metabolism, but c) higher 5-HT metabolism, reflected also in lower HVA/5HIAA ratios. It is tempting to interpret the lack of DA metabolic differences as reflecting the success of medication in countering hypodopaminergia. However, a lower NA and higher 5-HT turnover suggests also where medication has not normalized activity, despite the normalizing direction in which atypical neuroleptics act (see above). The fact that DA metabolism and the HVA/5-HIAA ratio negatively predicted and NA metabolism positively predicted DA D2-occupancy supports the attribution of the direction of change to the antipsychotic drug treatment. The opposite generalization would be that the patients exhibited lower catecholamine-ergic but higher serotonergic metabolism than normal. Consistent with this, Yoshimura et al (2000) found that where there was an improvement of negative symptoms (not usually a marked observation) MHPG increased correlating with the medication metabolite, and higher 5-HIAA levels were especially associated with patients showing a poor prognosis (Waring 1995). More surprising was our finding no predictive relationship between the monoaminergic measures and prolactin levels. Considering that DA antagonism raises (Bagli et al. 1999) while 5-HT antagonism lowers prolactin levels (Tuinier et al 1996), the data are likely confounded by both the heterogeneity of the patients (with putatively more and less of a 5HT impairment) and of the result of half being treated with drugs with a 5-HT antagonist action and half not.

\section{Paranoid vs. nonparanoid diagnoses:}

Relatively suppressed DA activity in paranoid patients was explained by the increased DA D2-receptor occupancy that this group exhibited, but suppressed NA activity and HVA/5-HIAA ratios survived controlling for this effect of medication. It could be argued that the higher HVA/5-HIAA ratio in paranoid patients reflected increased $5-\mathrm{HT}$ metabolism as reported for this group by Markianos et al (1992). Similarly the higher NA metabolism in the non-paranoid group may have reflected the negative symptoms not seen in the paranoid group, as Pickar et al (1990) reported. (Note, however that as NA turnover was still lower than in the healthy group, a positive effect of medication should still be reflected by an increase.) Increased sensitivity of the HT2a-receptor and subsensitive alpha-2 receptors have been hypothesized to be contributory factors in schizophrenia (e.g. Brambilla et al 1994). While these altered receptor states could underlie our results, our conclusions are limited by the absence of a suitable control for the binding of antipsychotic drugs to these receptors.

\section{More/less thought-disorder:}

Increased HVA/5-HIAA ratios were not explained by changes of DA metabolism, chlorpromazine equivalents (dose) nor DA D2occupancy, but related to the higher PRL levels seen in those with more thoughtdisorder. This cannot be explained by a disproportionate number of patients with much thought-disorder also being treated with typical neuroleptics that raise prolactin 
levels via DA D2 antagonism: 20 patients with severe thought disorder received typical and 24 atypical antipsychotic drugs, while 28 with low thought disorder received typical agents and 18 received atypical drugs. Thus a serotonergic mechanism is postulated. Indeed, a number of 5-HT receptor changes in schizophrenia have been detailed by Brunello et al (1995). Further, challenge studies with mchlorophenylpiperazine revealed that the symptoms of those with positive thoughtdisorder were the most sensitive (Krystal et al 1993), and gating and cognitive function have been related to 5-HT activity in disorganized patients with thought-disorder (Oades et al 2000a).

\section{The ideas-of-reference dimension (IoR):}

If loR are predominant among the symptoms then both DA and 5-HT turnover is more rapid than in those patients with few such symptoms: yet, the ratio of the two transmitter activities (HVA/5-HIAA) was also increased. Covariance with DA D2-receptor occupancy demonstrated the contribution of D2-antagonists to this result, while covariance with prolactin levels indicated a $5-\mathrm{HT}$ binding component to a treatment-induced change. However, it should be noted that the comparison with controls shows that while the changes were in the direction of normalization for the between-metabolite ratio, this was achieved by exaggerating the turnover response of both DA and 5-HT individually (cf. Figures 1 and 4). A parsimonious interpretation would be that while atypical medication, as shown above, tended to normalize the ratio of activity in the two monoaminergic systems, this was achieved at the expense of exaggerating the activity in the individual systems. While this may have ameliorated some clinical features, it may not have been productive for controlling loR.

The attribution of a role for DA, and possibly 5-HT activity to manifestations of delusional beliefs is not novel (Miller 1984), delusions were reported to be inversely related to DA uptake (Dean et al 1992), to prolactin release (Kulkarni et al 1990) and to DA infusions to a patient with Parkinson's disease (Kulkarni et al 1992). The limits to a similar interpretation of our present data lie firstly in that we cannot demonstrate whether the putative relationship of prolactin to $5-\mathrm{HT}$ activity postulated here is a direct one or occurs indirectly via DA mechanisms (cf. mesocortical DA modulation by serotonergic mechanisms, Rollema et al. 1997; Kuroki et al. 1999). Secondly, Zhang et al noted that although HVA levels correlated negatively with delusions in non-medicated patients, increased HVA levels may be indicative of more neuropathology. The present analysis cannot demonstrate a link between overall illness severity and DA activity. However, an attempt to control for the influence of increasing doses of antipsychotic drugs (chlorpromazine equivalents) did not remove the significance of the differences recorded between patients with more or fewer ideasof-reference.

In conclusion, we believe we have been able by exploratory control measures for the DA and 5-HT actions of medication to show that atypical antipsychotic drugs can exert a normalizing role on the HVA/5-HIAA metabolic ratios that are in general lower than in healthy subjects. Indeed these ratios are lower in paranoid vs. nonparanoid patients, in those with less thought disorder but more ideas-ofreference. Controlling for DA D2-occupancy and prolactin secretion implicates a serotonergic contribution to these differences, while still pointing to catecholaminergic (DA and NA) activity anomalies in the paranoid/nonparanoid distinction. The contributions of DA and 5-HT metabolism to the symptom dimensions of thought disorder and ideas-of reference has implications for the fine tuning of the treatment of choice for individuals depending on their predominant symptom dimensions. 


\section{References}

Alfredsson G, Wiesel F-A 1990. Relationship between clinical effects and monoamine metabolites and amino acids in sulpiridetreated schizophrenic patients. Psychopharmacology 101: 324-331.

American Psychiatric Association. Diagnostic and Statistical Manual of Mental Disorders (DSM-IV), $4^{\text {th }}$ ed., Washington, D.C.: American Psychiatric Association, 1994.

Amin F, Davidson M, Kahn RS, Schmeidler J, Stern R, Knott PJ, Apter SH.1995. Assessment of central dopaminergic index of plasma HVA in schizophrenia. Schizophr Bull 21: 53-66.

Andreasen NC, Olsen S. 1982. Negative versus positive schizophrenia: definition and validation. Arch Gen Psychiatry 39: 789-794.

Bagli $M$, Süverkrüp R, Höflich $G$, Kasper $S$, Möller H-J.Langer $M$, Barlage $U$, Rao ML. 1999. Pharmacokinetic-pharmaco-dynamic modelling of tolerance to the prolactinsecreting effect of chlorpro-thixene after different modes of drug administration. J Pharmacol Exp Ther 291: 547-554.

Bender S, Müller B, Oades RD, Sartory G. 2001. Conditioned blocking and schizophrenia: a replication and study of the role of symptoms, age, onset-age of psychosis and illness duration. Schizophr Res 49: 157-170.

Benkert O, Hippius H. 1986. Psychiatrische Pharmakotherapie $\left(4^{\text {th }}\right.$ ed.). SpringerVerlag, Heidelberg.

Bleich A, Brown S, Kahn R, Van Praag HM. 1988 The role of serotonin in schizophrenia. Schizophr Bull 14: 297-315.

Brambilla F, Marini S, Saito A, Fassone G, Picardi A, Nerozi D, Pancheri P. 1994. Noradrenergic and dopaminergic interrelation in schizophrenia. Psychiatry Res.53: 231-242.

Brauns H, Haun D, Steinmann S. 1997. The construction of an internationally comparable classification by class. Erwerbsstatistische Besonderheiten am Beispiel von Labour Force Surveys der Bundesrepublik Deutschland, Frankreichs, Großbritanniens und Ungarns. Arbeitspapiere Arbeitsbereich 1/22, Mannheim Center for European Social Research (MZES), Mannheim.
Breier A, Buchanan RW, Waltrip RW, Lostwak S, Holmes G, Goldstein DS. 1994. The effect of clozapine on plasma norepinephrine relationship to clinical efficacy. Neuropsychopharmacology 10: 1-7.

Breier A. 1999. Cognitive deficit in schizophrenia and its neurochemical basis. Br J Psychiatry 174: 16-18.

Brunello N, Masotto C, Steardo L, Markstein R, Racagni G. 1995. New insights into the biology of schizophrenia through the mechanism of action of clozapine. Neuropsychopharmacology 13: 177-213.

Carlsson A, Waters N, Carlsson ML. 1999. Neurotransmitter interactions in schizophrenia - therapeutic implications. Biol Psychiatry 46: 1388-1395.

Carpenter WT, Kirkpatrick B, Buchanan RW. 1999. Schizophrenia: syndromes and diseases. J Psychiat Res 33: 473-475.

Cartmell J, Salhoff CR, Perry KW, Monn JA, Schoepp DD. 2001. Dopamine and 5-HT turnover are increased by the $\mathrm{mGlu} 2 / 3$ receptor agonist LY379268 in rat medial prefrontal cortex, nucleus accumbens and striatum. Brain Res 887: 378-384.

Croonenberghs J, Delmeire L, Verkerk R, Lin AH, Meskal A, Neels H, Van der Plancken M, Scharpe S, Deboutte D, Pison G, Maes M. 2000. Peripheral markers of serotonergic and noradrenergic function in post-pubertal, Caucasian males with autistic disorder. Neuropsychopharmacology 22: 275-283.

Dean B, Kulkarni J, Copolov DL, Shrikanthan P, Malone V, Hill C. 1992. Dopamine uptake by platelets from subjects with schizophrenia: a correlation with the delusional state of the patient. Psychiatry Res 41: 17-24.

Dursun SM, Whitaker RP, Andrews H, Reveley MA. 1997. Effects of natural ageing on plasma 5-HT turnover in humans. Hum. Psychopharmacol., 12: 365-367.

Dursun SM, Szemis A, Andrews $H$, Whitaker RP, Reveley MA. 2000. Effects of clozapine and typical antipsychotic drugs on plasma 5HT turnover and impulsivity in patients with schizophrenia: a cross-sectional study. J Psychiatr Neurosci 25: 347-352.

Eriksson B-M, Persson B-A. 1982. Determination of catecholamines in rat heart tissue and plasma samples by liquid chromatography with electro-chemical detection. J Chromatogr 228: 143-154. 
Friedhoff AJ, Silva RR (1995) The effects of neuroleptics on homovanillic acid. In Psychopharmacology: the fourth generation of progress: Bloom FE, Kupfer DJ, (eds), Raven Press: New York:, 1229-1233.

Friedman JI, Adler DN, Davis KL. 1999. The role of norepinephrine in the pathophysiology of cognitive disorders: potential applications to the treatment of cognitive dysfunction in schizophrenia and Alzheimer's disease. Biol Psychiatry 46: 1243-1252.

Frith CD, Blakemore S-J, Wolpert DM. 2000. Explaining the symptoms of schizophrenia: abnormalities in the awareness of action. Brain Res Rev 31: 357-363

Fukuda M, Niwa S-I, Hiramatsu K-I, Hata A, Nakagome K, Iwanami A, Honda H. 1996. Exaggerated responsivity of brain dopaminergic system activity in schizophrenia: a preliminary finding of increased variance of plasma homovanillic acid level in a chronic patient. Schizophr Res 20: 241-244.

Galinowski A, Poirier MF, Aymard N, Leyris A, Beauverie P, Pourdel MC, Loo H. 1998. Evolution of plasma homovanillic acid (HVA) in chronic schizophrenic patients treated with haloperidol. Acta Psychiat Scand 97: 458-466.

Garver DL, Steinberg JL, McDermott BE, Yao JK, Ramberg JE, Lewis S, Kingsbury SJ. 1997. Etiologic heterogeneity of the psychoses: is there a dopamine psychosis? Neuropsychopharmacology 16: 191-201.

Gasperoni TL, Ekelund J, Huttunen MO, Lönnqvist J, Cannon TD. 2001. Catechol-Omethyl-transferase (COMT) genotype is associated with neuro-psychologic and brain morphometric variation in schizophrenia patients. Schizophr Res 49: 70.

Grace AA. 2000 Gating of information flow within the limbic system and the pathophysiology of schizophrenia. Brain Res Rev 31: 30-341.

Green Al, Alam MY, Sobieraj JT, Pappalardo KM, Waternaux C, Salzman C, Schatzberg AF, Schildkraut JJ.1993. Clozapine response and plasma catecholamines and their metabolites. Psychiatry Res 46: 139-149.

Greene KA, Faull KF. 1989. Relationship between plasma and cerebrospinal fluid norepinephrine and dopamine metabolites in a nonhuman primate. $J$ Neurochem 53: 1007-1013.

Gypta RN, Whelton C. 1992. Determination of plasma homovanillic acid by liquid chromatography with electrochemical detection. J Chromatogr 582: 236-241.

Jernej B, Banovic M, Cicin-Sain L, Hranilovic D, Balija M, Oreskovic D, Folnegovic-Smalc V. 2001. Physiological characteristics of platelet/ circulatory serotonin: study on a large human population. Psychiatry Res 94: 153-162.

Kane JM. 1996. Drug therapy: Schizophrenia. New England I Med 334: 34-41.

Kay SR, Opler LA, Fizbein A. The Positive and Negative Syndrome Scale (PANSS). Toronto: Manual. Multi-Health Systems 1992.

Kim Y-K, Kim L, Lee M-S. 2000. Relationships between interleukins, transmitters and psychopathology in drug-free male schizophrenics. Schizophr Res 44: 165-175.

Kopin IJ. 1992. Origins and significance of dopamine and catecholamine metabolites in body fluids. Pharmacopsychiatry 25: 3336.

Krystal JH, Seibyl JP, Price LH, Woods SW, Heninger GR, Aghajanian GH, Charney DS. 1993. $\mathrm{m}$-Chlorophenylpiperazine effects in neuroleptic-free schizophrenic patients: evidence implicating serotonergic systems in positive symptoms of schizophrenia. Arch Gen Psychiatry 50: 624-635.

Kulkarni J, Horne M, Butler E, Kerks N, Copolov DL. 1992. Psychotic symptoms resulting from intra-ventricular infusion of dopamine in Parkinson's disease. Biol Psychiatry 31: 1225-1227.

Kulkarni J, Keks NA, Stuart GW, Mackie B, Minas IH, Singh B, Copolov D. 1990. Relationship of psychotic symptoms to haloperidol-stimulated prolactin release. Acta Psychiatr Scand 82: 271-274.

Kuroki T, Meltzer HY, Ichikawa J. 1999. Effects of antipsychotic drugs on extracellular dopamine levels in the rat medial prefrontal cortex and nucleus accumbens. $J$ Pharmacol Exp Ther 288: 774-781.

Laruelle $M$, D'Souza CD, Baldwin RM, AbiDargham A, Kanes SJ, Fingado CL Seibyl JP, Zoghbi SS, Bowers $M B$, Jatlow $P$, Charney DS, Innis RB. 1997. Imaging D2 receptor occupancy by endogenous dopamine in 
humans. 17:162-174.

Liddle PF, Barnes TRE. 1999. Syndromes of chronic schizophrenia. Br J Psychiatry 157: 558-561.

Lieberman JA, Koreen AR. 1993. Neurochemistry and neuroendocrinology of schizophrenia: a selective review. Schizophr Bull 19: 371-429.

Maas JW, Hattoz SE, Greene NM, Landis DH. 1980. Estimates of dopamine and serotonin synthesis by the awake human brain. J Neurochem 34: 1547-1549

Maas J, Bowden CL, Miller AL, Javors MA, Funderburg LG, Berman N, Weintraub ST. 1997. Schizophrenia, psychosis and cerebral spinal fluid homovanillic acid concentrations. Schizophr Bull 23: 147-154.

Magaro PA, Chamrad DL. 1983. Hemispheric preference of paranoid and nonparanoid schizophrenics. Biol Psychiatry 18: 12691285.

Markianos M, Botsis A, Avanitis Y. 1992. Biogenic amine metabolites in plasma of drug-naive schizophrenic patients: associations with symptomatology. Biol Psychiatry 32: 288-292.

Miller R. 1984. Major psychosis and dopamine: controversial features and some suggestions. Psychol Med 14: 779789.

Minegishi A, Ishizaki T. 1984. Determination of free 3-methoxy-4-hydroxyphenylglycol with several other monoamine metabolites in plasma by high-performance liquid chromatography with amperometric detection. J Chromatogr 311: 51-57.

Mück-Seeler D, Pivac N, Jakovljevic M, Brzovic Z. 1999. Platelet serotonin, plasma cortisol and dexamethasone suppression test in schizophrenic patients. Biol Psychiatry 45: 1433-1439.

Nagamoto HT, Adler LE, McRae KA, Huettl P, Cawthra E, Gerhardt G, Hea R, Griffith J. 1999. Auditory P50 in schizophrenics on clozapine: improved gating parallels clinical improvement and changes in plasma 3methoxy-4-hydroxyphenylglycol.

Neuropsycho-biology 39: 10-17.

Nibuya M, Kanba S, Sekiya U, Suzuki E, Matsu Y, Kinishita N, Shintani N, Yagi G, Asai M. 1995. Schizophrenic patients with deficit syndrome have higher plasma homovanillic acid concentrations and ventricular enlargement. Biol Psychiatry 38: 50-56.

Oades RD. Attention and Schizophrenia: Neurobiological Bases. Pitman, London, 1982

Oades RD, Müller B, Schall U, Bender S, Wolstein J. 2000a. Automatic vs. controlled attention in schizophrenia: conditioned blocking and sensory gating. Behav Pharmacology 11: 346.

Oades RD, Rao ML, Bender S, Sartory G, Müller BW. 2000b. Neuropsychological and conditioned blocking performance in patients with schizophrenia: assessment of the contribution of neuroleptic dose, serum levels and dopamine D2-receptor occupancy. Behav Pharmacology 11: 317330.

Ottong SE, Garver DL. 1997. A bimodal distribution of plasma HVA/MHPG in the psychoses. Psychiatry Res 69: 97-103.

Pickar D, Breier A, Hsiao JK, Doran AR, Wolkowitz OM, Pato CN, Konicji E, Potter WZ. 1990. Cerebrospinal fluid and plasma monoamine metabolites and their relation to psychosis. Arch Gen Psychiat 47: 641648.

Rao ML. 1986. Modification of the radioreceptor assay technique for estimation of serum neuroleptic drug levels leads to improved precision and sensitivity. Psychopharmacology 90: 548-553.

Rao ML, Gross G, Strebel B, Braunig P, Huber G, Klosterkötter J. 1990. Serum amino acids, central monoamines and hormones in drugnaive, drug-free and neuroleptic treated schizophrenic patients. Psychiatry Res 34: 243-257.

Rey M-J, Schulz P, Costa C, Dick P Tissot R. 1989. Guidelines for the dosage of neuroleptics. $\quad 1$ : Chlorpromazine equivalents of orally administered neuroleptics. Int Clin Psychopharmacology 4: 95-104.

Reynolds GP (1995): Neurotransmitter systems in schizophrenia. Int Rev Neurobiology 38:305-339.

Ribeyre J-M, Lesieur P, Dollfus S, Gregoire A, Varoquaux O, Menard J-F, Petit M. 1991. Influence of Parkinsonism and negative symptomatology on plasma HVA levels in neuroleptic-treated schizophrenic patients. Biol Psychiatry 29: 397. 
Rollema H, Lu Y, Schmidt AW, Zorn SH. 1997. Clozapine increases dopamine in prefrontal cortex by 5 -HT1A receptor activation. Eur J Pharmacology 338: R3-R6

Schulz E, Remschmidt H, Fleischhaker C. 1994. Der Einfluss von Clozapin auf die biogenen Amine im Rahmen der medikamentosen Behandlung von schizophrenen Psychosen des Jugendalters. $Z$ Kind Jugendpsychiatrie 22: 285-298.

Schulz E, Fleischaker C, Clement H-W, Remschmidt H. 1997. Blood biogenic amines during clozapine treatment of early onset schizophrenia J Neur Transm (GenSect) 104: 1077-1089.

Schulz P, Rey M-J, Dick P, Tissot R. 1989. Guidelines for the dosage of neuroleptics. II: Changing from daily oral to long-acting injectable neuroleptics. Int Clin Psychopharm-acology 4: 105-114.

Sharma RP, Javaid JI, Davis JM, Janicak PG. 1998. Pretreatment plasma homovanillic acid in schizophrenia and schizoaffective disorder: the influence of demographic variables and the inpatient drug-free period. Biol Psychiatry 44: 488-492.

Sternberg DE, Heninger GR, Roth RH. 1983. Plasma homovanillic acid as an index of brain dopamine metabolism: enhancement with debrisoquin. Life Sci 32: 2447-2252.

Sumiyoshi T, Hasegawa $M$, Jayathilake $K$, Meltzer HY. 1997. Prediction of short-term changes in symptom severity by baseline homovanillic acid levels in schizophrenic patients receiving clozapine. Psychiat Res 69: 113-121.

Suzuki E, Kanba S, Nibuya M, Koshikawa H, Nakaki T, Yagi G. 1992. Plasma homovanillic acid, plasma anti-D1 and D2 dopaminergic receptor activity, and negative symptoms in chronically medicated schizophrenia. Biol Psychiatry 31: 357-365.

Thibaut F, Ribeyre J-M, Dourmap N, Menard JF, Dollfus S, Petit M. 1998. Plasma 3methoxy-4-hydroxyphenyl-glycol and homovanillic acid measurement in deficit and non-deficit forms of schizophrenia. Biol Psychiatry 43: 24-30.

Tuinier S, Verhoeven WMA, Van Praag HM 1996. Serotonin and disruptive behaviour: a critical evaluation of the clinical data. Hum Psychopharmacology 11: 469-482.
Waring EM (1995): The psychobiology of firstepisode schizophrenia. Canad J Psychiatry 40:33-37.

Yoshimura R, Nakamura J, Ueda N, Trao T (2000) Effect of risperidone on plasma free 3-methoxy-4-hydroxy-phenylglycol (pMHPG) levels in schizophrenic patients: relationship among plasma concentrations of risperidone and 9-hydroxyrisperidone, pMHPG levels and clinical improvement. Int Clin Psychopharmacology 15:175-180.

Zhang ZJ, Peet $M$, Ramchand $C N$, Shah $S$, Reynolds GP. 2001. Plasma homovanillic acid in untreated schizophrenia relationship with symptomatology and sex.
J
Res
35:23-38 
